\title{
Surgical treatment of adolescent idiopathic scoliosis in the United States from 1997 to 2012: an analysis of 20,346 patients
}

\author{
Hari T. Vigneswaran, BS, Zachary J. Grabel, MD, Craig P. Eberson, MD, Mark A. Palumbo, MD, and \\ Alan H. Daniels, MD
}

Department of Orthopaedics, Alpert Medical School of Brown University, and Rhode Island Hospital, Providence, Rhode Island

OBJECT Adolescent idiopathic scoliosis (AIS) can cause substantial morbidity and may require surgical intervention. In this study, the authors aimed to evaluate US trends in operative AIS as well as patient comorbidities, operative approach, in-hospital complications, hospital length of stay (LOS), and hospital charges in the US for the period from 1997 to 2012.

METHODS Patients with AIS (ICD-9-CM diagnosis codes 737.30) who had undergone spinal fusion (ICD-9-CM procedure codes 81.xx) from 1997 to 2012 were identified from the Kids' Inpatient Database. Parameters of interest included patient comorbidities, operative approach (posterior, anterior, or combined anteroposterior), in-hospital complications, hospital LOS, and hospital charges.

RESULTS The authors identified 20,346 patients in the age range of 0-21 years who had been admitted for AIS surgery in the defined study period. Posterior fusions composed $63.4 \%$ of procedures in 1997 and $94.1 \%$ in $2012(r=0.95$, $p<0.01)$. The mean number of comorbidities among all fusion groups increased from 3.0 in 1997 to 4.2 in $2012(r=0.92$, $p=0.01$ ). The percentage of patients with complications increased from $15.6 \%$ in 1997 to $22.3 \%$ in $2012(r=0.78, p=$ 0.07). The average hospital LOS decreased from 6.5 days in 1997 to 5.6 days in $2012(r=-0.86, p=0.03)$. From 1997 to 2012, the mean hospital charges (adjusted to 2012 US dollars) for surgical treatment of AIS more than tripled from $\$ 55,495$ in 1997 to $\$ 177,176$ in $2012(r=0.99, p<0.01)$.

CONCLUSIONS Over the 15-year period considered in this study, there was an increasing trend toward using posteriorbased techniques for AIS corrective surgery. The number of comorbid conditions per patient and thus the medical complexity of patients treated for AIS have increased. The mean charges for the treatment of AIS have increased, with a national bill over $\$ 1.1$ billion per year in 2012.

http://thejns.org/doi/abs/10.3171/2015.3.PEDS14649

KEY WORDS scoliosis; pediatric spinal surgery; pedicle screw; hospital charge; complications; spine

A DOLESCENT idiopathic scoliosis (AIS) can cause substantial morbidity in patients and may require surgical intervention. $1,6,12,14-17,19,21,22,24,25,28,30,31,33$ If the condition is left untreated or undertreated, curve progression, ${ }^{19}$ pulmonary dysfunction,,${ }^{33}$ back pain, ${ }^{25}$ and negative impacts on self image can occur. ${ }^{26}$ Providing appropriate treatment for AIS is critical in optimizing long-term clinical outcomes. ${ }^{15,17,23,29,31,32}$
The surgical care of AIS has been revolutionized by the advent of pedicle screw technology, ${ }^{1,3,11,20}$ surgical navigation, ${ }^{16}$ derotation techniques, ${ }^{21}$ arthrodesis enhancement,${ }^{13}$ and various growing-rod technologies. ${ }^{4,6}$ While long-term health-related quality of life studies are needed to fully understand the effects of operative intervention, outcomes in children following spinal deformity surgery are generally positive. ${ }^{1,10,14,15,17,22}$

\footnotetext{
ABBREVIATIONS AHRQ = Agency for Healthcare Research and Quality; AIS = adolescent idiopathic scoliosis; HCUP = Healthcare Cost and Utilization Project; KID = Kids' Inpatient Database; LOS = length of stay.

SUBMITTED November 12, 2014. ACCEPTED March 20, 2015.

NCLUDE WHEN CITING Published online June 26, 2015; DOI: 10.3171/2015.3.PEDS14649.

DISCLOSURE The authors report no conflict of interest concerning the materials or methods used in this paper or the findings specified in this paper. Dr. Daniels is a consultant for Stryker and Osseus. Dr. Ebberson is a consultant for Orthofix Spine; receives royalties from Globus Medical; and is part of the speakers bureau of Medtronic, DePuy, and Stryker. Dr. Palumbo is a consultant for Stryker and has received support from Globus Medical for non-study-related clinical or research efforts overseen by him.
} 
Surgical techniques are well described for both the anterior and posterior approach to spinal instrumentation and arthrodesis. Anterior procedures gained popularity in the 1990s and 2000s..$^{12,28}$ In recent years, instrumented posterior fusion has been performed with greater regularity for the treatment of AIS.,14,16,17,20-22 The relative proportion of anterior versus posterior procedures for patients with AIS was previously investigated by Martin et al.,18 who described the rising use of posterior-based techniques as well as the increasing charges associated with inpatient surgical care, although they did not report comorbidity or complication data.

In the present study, we aimed to evaluate US trends in operative AIS as well as patient comorbidities, operative approach, in-hospital complications, hospital length of stay (LOS), and hospital charges in the US for the period from 1997 to 2012. We hypothesized that the rate of posterior-based surgery would be increasing compared with the rates for anterior-based surgery or a combined approach and that the hospital LOS, charges, and in-hospital complications would be lower in patients who underwent posterior surgery than in those who underwent anterior surgery.

\section{Methods \\ Data Source}

The Healthcare Cost and Utilization Project (HCUP) Kids' Inpatient Database (KID) for the years 1997 to 2012 was used for this study. This database was developed by the US Agency for Healthcare Research and Quality (AHRQ) as part of a partnership among industry, federal, and state agencies to help track and analyze trends in health care utilization, cost, quality, and outcomes. The KID contains national estimates of hospital inpatient stays for patients younger than 21 years of age and includes discharges from over 4000 US hospitals annually. The KID data are available every 3 years from 1997 to 2012 and comprises up to 7 million patients annually from 44 states. Procedure and diagnostic codes are classified according to the ICD-9-CM. Patient-specific demographic data and hospitalization information coded by synthetic identifiers are also available.

\section{Patient Selection}

We performed a retrospective analysis using hospital discharge data from the KID for the period from 1997 to 2012. Using IBM SPSS statistics software and the ICD-9CM diagnosis codes, we identified children with a diagnosis of idiopathic scoliosis (737.30). Patients with any of the following ICD-9-CM procedure codes were included in the study: cervical level, 81.02, 81.03, 81.32, 81.33; thoracolumbar level, 81.04, 81.05, 81.34, 81.35; and lumbosacral level, 81.06, 81.07, 81.08, 81.36, 81.37, 81.38. Patients were also separated into those who underwent anterior spinal fusion $(81.02,81.04,81.06,81.08,81.32,81.34,81.36$, 81.38 ) and those who underwent posterior fusion (81.03, $81.05,81.07,81.33,81.35,81.37)$. Those who underwent both an anterior and posterior fusion were included in a separate cohort.

\section{Patient Demographics}

We examined patient mortality, number of assigned discharge diagnoses, hospital LOS, expected primary payer (Medicare, Medicaid, private insurance, self-pay, or no charge), and total hospital charge in US dollars. Dollar figures were adjusted to 2012 values utilizing the US Department of Labor Bureau of Labor Statistics Inflation Calculator (http://www.bls.gov/data/inflation_calculator. htm).

Complications were noted if any of the following diagnoses were made during a patient's hospitalization: accidental puncture or laceration of the dura mater during a procedure (749.31), nervous system complication (997.01, 997.02, 997.09), operative field and wound management complication $(998.11,998.12,998.13,998.30)$, deep venous thrombosis or pulmonary embolus complication (415.11, 415.12, 415.13, 415.19, 453.40, 453.41, 453.42, 453.81, 453.82, 453.83), infectious complication (998.51, 998.59, 486, 599.0; which was further divided into wound infection, pneumonia, and urinary tract infection), and any complication or blood loss that required transfusion of packed cells (99.04). ${ }^{34}$

\section{Data Analysis}

Patients in the cohort who were 18 years or younger were used to determine the incidence of spinal deformity surgery per year. Using a weighted KID population calculation determined by the AHRQ, we figured national estimates for children younger than 18 years who had undergone AIS fusion surgery. The US population 18 years and under was determined from the US Census Bureau. Other than incidence calculations, the research protocol included patients 21 years and younger because we determined that the majority of patients undergoing these operations were most likely to have AIS before the age of 18 years.

Patients who underwent anterior column fusion, posterior column fusion, and combined anteroposterior column fusion were separated within each year and compared in terms of mortality, number of discharge diagnoses, LOS, in-hospital complications, and hospital charges. Mean total charges for each year were adjusted for inflation according to year 2012 values. The proportion of predicted primary payer type was also analyzed. A linear regression of mean hospital charges for all inpatient admissions in the KID, regardless of diagnosis, was trended to examine health care "inflation" over time. This group represented any child admitted to the hospital and served as a control to compare charges for undergoing fusions in a temporal relationship.

A statistical analysis of continuous and categorical outcome variables was performed using unpaired t-tests and chi-square tests with Yates' correction. Linear regression analysis was completed using Pearson correlation coefficients with 2 -sided $\mathrm{p}$ values with a statistical cutoff of $\mathrm{p}<$ 0.05 , set a priori. Crude odds ratios with $95 \%$ confidence intervals and z statistics were determined where appropriate with a statistical cutoff of $\mathrm{p}<0.05$, set a priori. Statistical analysis was performed using SPSS version 22 (IBM Corp.). 


\section{Results \\ Study Cohort}

We identified a total of 20,346 patients in the age range of 0-21 years who had been admitted for inpatient surgery for AIS from 1997 to 2012 (Table 1). Within this cohort, a subpopulation of 18,649 patients was 18 years or younger. The incidence of pediatric surgery for AIS increased from 0.58 admissions/10,000 individuals in 1997 to 0.74 admissions $/ 10,000$ individuals per year in $2012(\mathrm{r}=0.91$, $\mathrm{p}=0.01$ ). The mortality rate was under $0.3 \%$ for all years examined. The mean number of discharge diagnoses increased from 3.0 in 1997 to 4.2 in $2012(r=0.92, p=0.01)$. The average hospital LOS decreased from 6.5 days in 1997 to 5.6 days in $2012(\mathrm{r}=-0.86, \mathrm{p}=0.03)$.

\section{Expected Payer and Hospital Charges}

Private insurers were the expected payer in $75 \%$ of admissions in 1997, a rate that decreased to $63 \%$ in 2012 $(r=-0.96, p<0.01 ;$ Fig. 1). Medicaid was the next most common expected payer, covering $17.7 \%$ of admissions in 1997 and increasing to $29.9 \%$ in $2012(\mathrm{r}=0.99, \mathrm{p}<0.01)$.

In the 15 -year study period, the mean hospital charges for the surgical treatment of AIS, adjusted to 2012 US dollars, more than tripled from $\$ 55,495$ in 1997 to $\$ 177,176$ in 2012 ( $r=0.99, \mathrm{p}<0.01$; Fig. 2). In comparison, in the control group of all admissions in the KID database, there was a lower increase of just 2-fold from \$13,416 in 1997 to $\$ 31,159$ in 2012.

The estimated national aggregate of inpatient charges for all pediatric patients undergoing surgery for AIS was \$228 million in 1997 compared with $\$ 1.132$ billion in 2012, a more than 4-fold increase in national charges.

\section{AIS Corrective Surgery Complications and Mortality}

The complication rate increased from $15.6 \%$ in 1997 to $22.3 \%$ in $2012(\mathrm{r}=0.78, \mathrm{p}=0.07)$. The primary etiology for inpatient complications after the correction of AIS was transfusion of cells, which occurred at an incidence of $11.1 \%$ in 1997 and increased to $19.5 \%$ in 2012 ( $\mathrm{r}=0.70$, $\mathrm{p}=0.12$ ). An infectious complication, which included pneumonia, urinary tract infection, or wound infection, was the second most likely complication. The rate of patients with infectious complications ranged from $2.8 \%$ in 1997 to $2.1 \%$ in $2012(\mathrm{r}=0.75, \mathrm{p}=0.09)$. Operative field and wound management complications (such as excessive

TABLE 1. Patients with AIS undergoing surgical fusions*

\begin{tabular}{|c|c|c|c|c|c|c|}
\hline \multirow[b]{2}{*}{ Parameter } & \multicolumn{6}{|c|}{ Year } \\
\hline & 1997 & 2000 & 2003 & 2006 & 2009 & 2012 \\
\hline No. of patients w/ surgical correction & 1783 & 2383 & 3069 & 3550 & 4333 & 5228 \\
\hline Mean LOS in days $†$ & $6.5( \pm 5.2)$ & $6.2( \pm 3.9)$ & $6.6( \pm 6.2)$ & $6.0( \pm 5.1)$ & $5.7( \pm 4.9)$ & $5.6( \pm 5.7)$ \\
\hline Mean no. of discharge diagnoses $\ddagger$ & $3.0( \pm 2.3)$ & $2.9( \pm 2.4)$ & $3.1( \pm 2.4)$ & $3.3( \pm 2.9)$ & $3.6( \pm 3.2)$ & $4.2( \pm 3.7)$ \\
\hline Patients w/ complications (no.) & $15.65 \%(279)$ & $19.22 \%(458)$ & $23.13 \%(710)$ & $24.03 \%(853)$ & $27.03 \%(1171)$ & $22.32 \%(1167)$ \\
\hline Mortality (no.) & $0.22 \%(4)$ & $0.17 \%(4)$ & $0.13 \%(4)$ & $0.09 \%(3)$ & $0.02 \%(1)$ & $0.10 \%(5)$ \\
\hline \multicolumn{7}{|l|}{ Anterior fusion } \\
\hline Patients (no.) $\S$ & $21.8 \%(388)$ & $23.6 \%(562)$ & $19.0 \%(584)$ & $13.6 \%(484)$ & $8.8 \%(383)$ & $3.3 \%(171)$ \\
\hline Mean LOS in days & $6.4( \pm 4.7)$ & $6.3( \pm 4.4)$ & $6.4( \pm 5.3)$ & $5.8( \pm 3.4)$ & $5.6( \pm 7.4)$ & $6.5( \pm 8.5)$ \\
\hline Mean no. of discharge diagnoses & $3.0( \pm 2.1)$ & $2.8( \pm 2.1)$ & $3.2( \pm 2.4)$ & $3.4( \pm 2.7)$ & $3.6( \pm 2.8)$ & $4.7( \pm 4.0)$ \\
\hline Patients w/ complications (no.) & $15.2 \%(59)$ & $12.6 \%(71)$ & $18.8 \%(110)$ & $19.4 \%(94)$ & $19.3 \%(74)$ & $20.5 \%(35)$ \\
\hline \multicolumn{7}{|l|}{ Posterior fusion } \\
\hline Patients (no.)†† & $63.4 \%(1130)$ & $62.1 \%(1480)$ & $65.6 \%(2013)$ & $76.7 \%(2722)$ & $85.4 \%(3700)$ & $94.1 \%(4917)$ \\
\hline Mean LOS in days & $5.8( \pm 3.0)$ & $5.6( \pm 2.7)$ & $5.9( \pm 4.2)$ & $5.8( \pm 5.0)$ & $5.5( \pm 3.9)$ & $5.4( \pm 5.0)$ \\
\hline Mean no. of discharge diagnosesf & $2.8( \pm 2.1)$ & $2.7( \pm 2.2)$ & $2.9( \pm 2.2)$ & $3.1( \pm 2.7)$ & $3.5( \pm 3.1)$ & $4.1( \pm 3.6)$ \\
\hline Patients w/ complications (no.) & $14.5 \%(164)$ & $18.8 \%(278)$ & $21.7 \%(436)$ & $23.2 \%(633)$ & $27.3 \%(1010)$ & $22.0 \%(1080)$ \\
\hline \multicolumn{7}{|l|}{ Anteroposterior fusion } \\
\hline Patients (no.) $\ddagger \ddagger$ & $14.9 \%(265)$ & $14.3 \%(341)$ & $15.4 \%(472)$ & $9.7 \%(344)$ & $5.8 \%(250)$ & $2.7 \%(140)$ \\
\hline Mean LOS in days & $9.8( \pm 10.1)$ & $8.4( \pm 6.2)$ & $10.1( \pm 11.2)$ & $8.3( \pm 6.9)$ & $9.0( \pm 9.7)$ & $10.2( \pm 15.7)$ \\
\hline Mean no. of discharge diagnoses $\S \S$ & $4.3( \pm 3.3)$ & $4.2( \pm 3.1)$ & $4.1( \pm 3.0)$ & $5.1( \pm 3.7)$ & $5.9( \pm 4.3)$ & $6.4( \pm 4.4)$ \\
\hline Patients w/ complications (no.)ףT & $21.1 \%(56)$ & $32.0 \%(109)$ & $34.8 \%(164)$ & $36.6 \%(126)$ & $34.8 \%(87)$ & $37.1 \%(52)$ \\
\hline \multicolumn{7}{|c|}{ 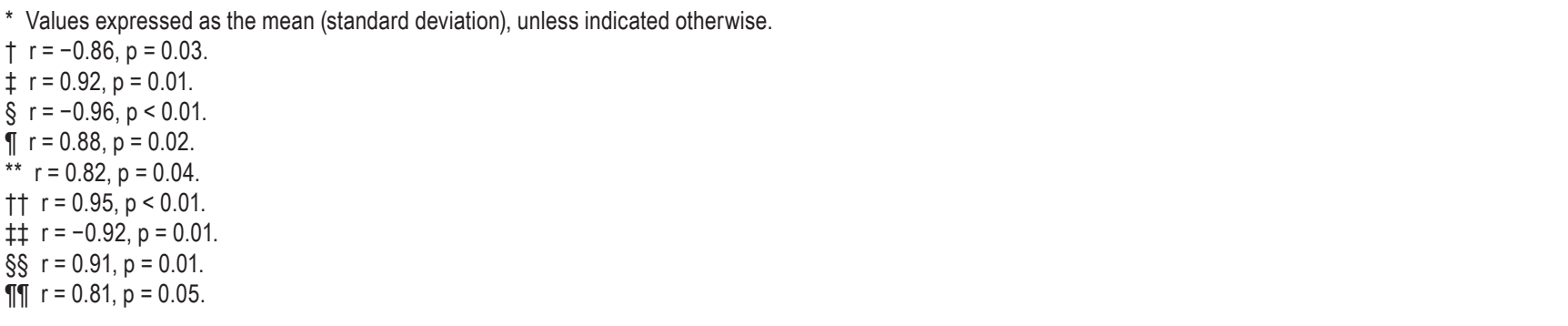 } \\
\hline
\end{tabular}




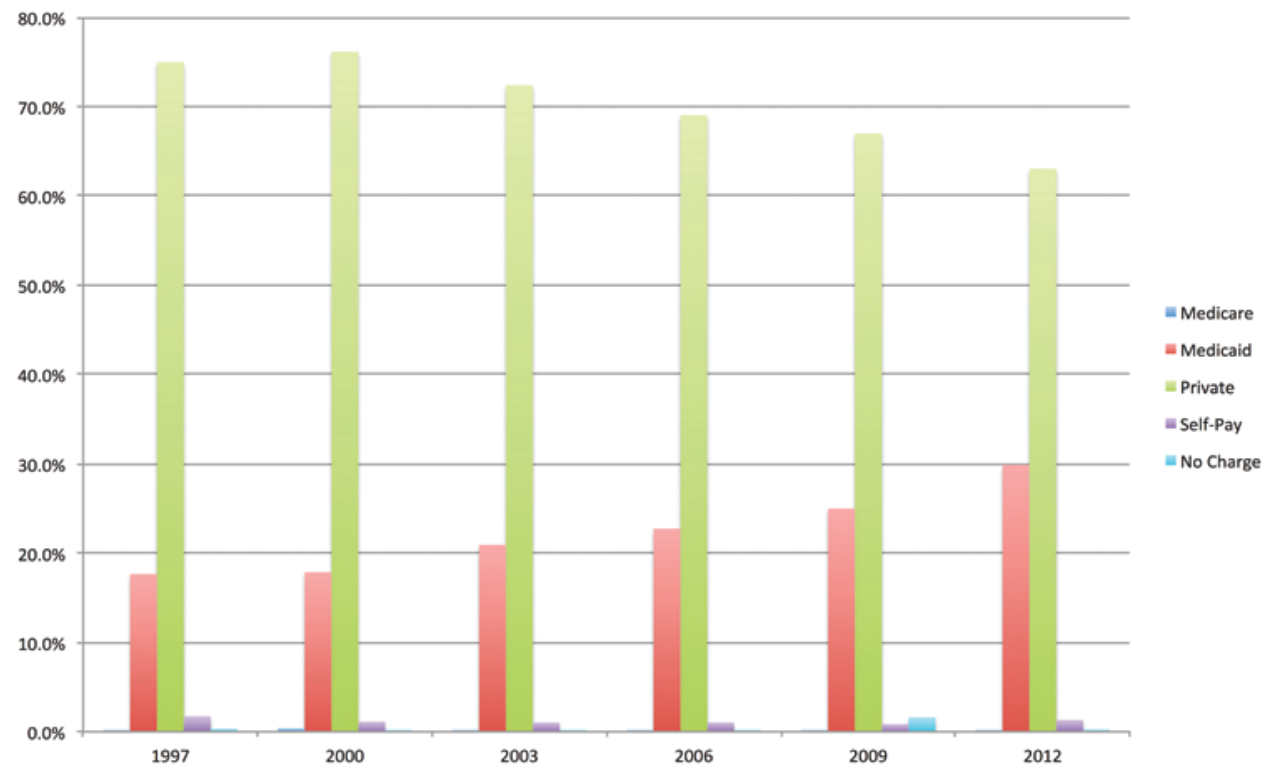

FIG. 1. Primary payer of inpatient admission charges for surgical care of patients with AIS treated using spinal fusion. Figure is available in color online only.

hemorrhage, hematoma, or seroma within the operative field) or wound disruption occurred at an incidence of $2.4 \%$ in 1997 but decreased to $1.7 \%$ in $2012(\mathrm{r}=-0.81$, $\mathrm{p}$ $<0.05)$. Other complications such as iatrogenic dural tear and/or CSF leakage, neurological injury, deep vein thrombosis, or pulmonary embolus all occurred at incidences < $1.0 \%$ for all years studied.

In the 15-year study period, 21 patients died during hospitalization after surgical treatment for AIS. The mortality rate decreased from $0.22 \%$ in 1997 to $0.10 \%$ in 2012 (r = $-0.86, p=0.03)$. In comparison with the surviving cohort, the OR of death after transfusion was 2.51 (95\% CI 1.03$6.05, \mathrm{p}=0.04)$; after infection, 6.95 (95\% CI 2.04-23.67, $\mathrm{p}$
$<0.01$ ); and after an operative field or wound management complication, 11.63 (95\% CI 3.90-34.72, p < 0.01).

\section{Anterior Versus Posterior Spinal Fusions}

The rate of anterior fusions decreased from $21.8 \%$ of procedures in 1997 to $3.3 \%$ in $2012(\mathrm{r}=-0.96, \mathrm{p}<0.01$; Table 1). Conversely, posterior fusions increased from $63.4 \%$ of procedures in 1997 to $94.1 \%$ in 2012 ( $\mathrm{r}=0.95, \mathrm{p}$ $<0.01$; Fig. 3).

Hospital LOS in patients who underwent anterior fusion ranged from 6.4 days in 1997 to 6.5 days in $2012(\mathrm{r}=$ $-0.32, \mathrm{p}=0.54)$. In patients who underwent posterior fusions, the LOS ranged from 5.8 days in 1997 to 5.4 in 2012

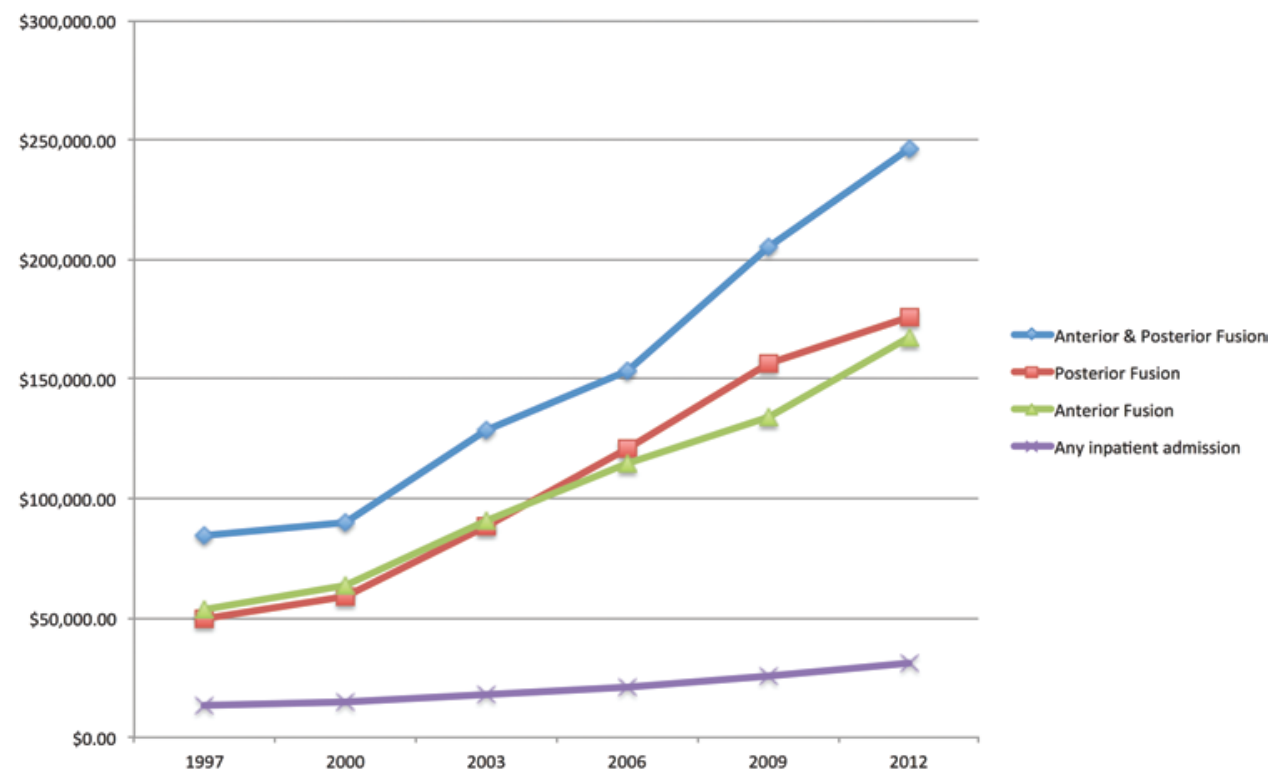

FIG. 2. Mean hospital charges for each child undergoing surgery for AIS. All charges were adjusted for inflation according to year 2012 values. "Any inpatient admission" refers to the control group. Figure is available in color online only. 


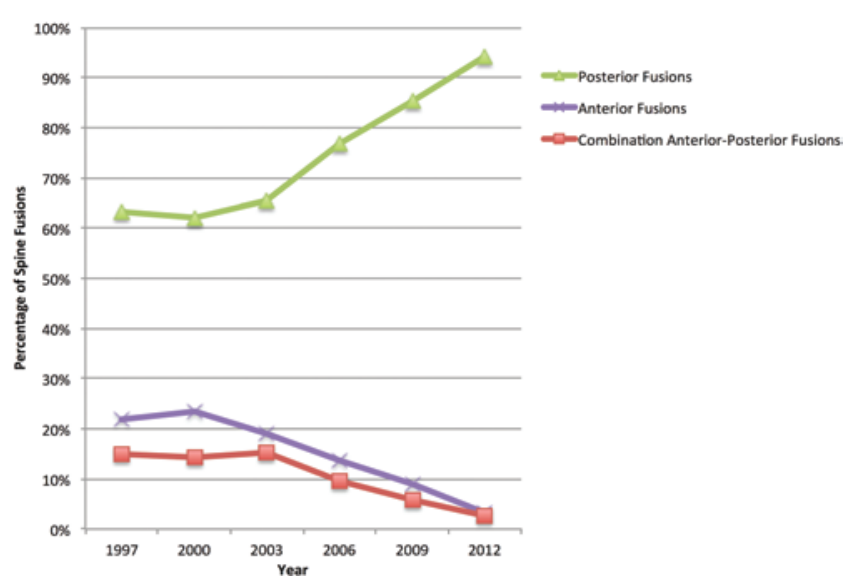

FIG. 3. Adolescent idiopathic scoliosis treated with anterior fusion, posterior fusion, or anteroposterior fusion, 1997-2012. Figure is available in color online only.

$(\mathrm{r}=-0.65, \mathrm{p}=0.16$; unpaired t-test with $\mathrm{p}<0.01$; Table 1). The mean number of discharge diagnoses for patients who underwent an anterior fusion ranged from 3.0 in 1997 to 4.7 in 2012 ( $\mathrm{r}=0.88, \mathrm{p}=0.02)$. The mean number of discharge diagnoses for patients who underwent posterior fusions ranged from 2.8 in 1997 to 4.1 in $2012(\mathrm{r}=0.92$, $\mathrm{p}$ $=0.01 ;$ unpaired t-test with $\mathrm{p}=0.03$ ).

Mean charges for patients admitted for anterior and posterior fusions were $\$ 53,453$ and $\$ 49,424$, respectively, in 1997 (unpaired t-test with $\mathrm{p}<0.0001$; Fig. 2). In 2012, the mean charges for patients admitted for anterior and posterior fusions were $\$ 167,130$ and $\$ 175,570$, respectively (unpaired t-test with $\mathrm{p}=0.291$ ).

In 1997, anterior fusions were associated with a complication rate of $15.2 \%$ compared with $14.5 \%$ for posterior fusions $(\mathrm{p}=0.80)$. In 2012, the complication rates were $20.5 \%$ and $22.0 \%$, respectively $(\mathrm{p}=0.71)$. Blood transfusions were the most commonly reported complication for patients in both the anterior and posterior fusion groups. In 1997, anterior fusions were associated with a transfusion rate of $11.3 \%$; posterior fusions, with a transfusion rate of $17.5 \%(p=0.01)$. In 2012, transfusion rates for anterior and posterior fusions were $15.8 \%$ and $19.3 \%$, respectively $(\mathrm{p}=$ 0.30 ). Infection was the second most common complication in the 2 groups. In 1997, anterior and posterior fusions were associated with infection rates of $2.6 \%$ and $4.4 \%$, respectively $(\mathrm{p}=0.14)$; in 2012, the infection rates were $4.7 \%$ and $2.0 \%$, respectively $(\mathrm{p}=0.03)$. The mortality rate associated for the 2 groups was $0.08 \%$ and $0.06 \%$, respectively, over the 15 -year study period $(\mathrm{r}=-0.19, \mathrm{p}=0.71)$.

\section{Combination Anteroposterior Spinal Fusions}

Patients who underwent combined anteroposterior spinal fusions composed $14.9 \%$ of those with spinal deformity in 1997, compared with only $2.7 \%$ in $2012(\mathrm{r}=$ $-0.92, p=0.01$; Fig. 3). These patients were also found to have a longer LOS, more diagnosed conditions, and higher hospital charges, which were all significant when comparing within the anterior and posterior fusion subgroups ( $\mathrm{p}$ $=0.0001$ for all). Hospital LOS for patients undergoing the combination fusion ranged from 9.8 in 1997 to 10.2 in $2012(\mathrm{r}=0.13, \mathrm{p}=0.81$; Table 1$)$. The number of comorbid conditions in patients who underwent anteroposterior fusion increased from 4.3 in 1997 to 6.4 in $2012(\mathrm{r}=0.91$, $\mathrm{p}=$ $0.01)$. Hospital charges for patients who underwent an anteroposterior fusion were $\$ 84,376$ in 1997 and $\$ 246,298$ in 2012 (Fig. 2). In terms of complications, $21.1 \%$ of patients in 1997 had at least one complication; when compared with aggregate anterior and aggregate posterior fusions, there was a significant difference (unpaired t-test with $\mathrm{p}=$ 0.01). In 2012, the complication rate in those who underwent anteroposterior fusion was $37.1 \%(\mathrm{p}<0.0001)$. Over time, the percentage of patients with a complication from this combination surgery increased significantly $(r=0.81$, $p=0.05)$. The mortality rate for patients who underwent anteroposterior fusion was $0.5 \%$, which was significantly higher than the rate for those who underwent isolated anterior or posterior fusion $(0.06 \% ; \mathrm{p}<0.0001)$.

\section{Discussion}

In this study we evaluated US trends in the surgical treatment of AIS from 1997 to 2012. The study revealed an increased rate of surgery for AIS as well as an increase in the use of posterior-based surgical techniques, the number of patient comorbidities, and the inflation-corrected mean hospital charges over time.

A previous study by Martin et al. examined patients with AIS and reported findings that support our conclusions that posterior-based techniques are increasing compared with anterior and anteroposterior techniques and that surgical care of AIS is becoming more costly. ${ }^{18} \mathrm{We}$ also examined comorbid conditions in this population and found an increasing trend toward more comorbid conditions in all patients with AIS who underwent corrective surgery. Throughout the 15-year study period, patients who underwent anteroposterior fusion had the greatest number of comorbid conditions, whereas patients who underwent posterior fusions had the fewest such conditions. Patients who underwent anteroposterior fusion may have had more severe spinal curves, which could lead to comorbid conditions, although this assertion cannot be proven with billing (HCUP KID) data alone.

A systematic review ${ }^{30}$ by Weiss and Goodall revealed a complication rate from scoliosis surgery ranging from $0 \%$ to $89 \%$. Potential explanations for the wide range of reported rates include heterogeneity in the patient populations, the lack of a standard definition of complication, and variable follow-ups. Their investigation revealed inhospital complication rates of 6.3\%-17.8\%, depending on the year examined and the surgical approach. Patients who had undergone the anteroposterior fusion had the highest complication rates. These data further suggest that patients who undergo anteroposterior fusion represent a more medically complex group. In 1997, patients with AIS who had undergone anterior fusions had more complications than those who had undergone posterior fusions. In each successive year studied, however, a higher complication rate was reported for patients who underwent posterior fusion. This result is probably explained by the higher transfusion rate associated with posterior fusions.

Hospital inpatient charges for AIS admissions increased from 1997 to 2012, even after adjusting for inflation. It is 
estimated that the inpatient hospital charges for surgical treatment of AIS nationwide was more than $\$ 1.1$ billion in 2012 alone. Anteroposterior fusions were associated with the highest hospital charges over the 15-year study period. This may be attributable to a higher complication rate, longer LOS, and larger patient population. Posterior fusions were associated with the second highest hospital charges, and anterior fusions were the least costly. Posterior fusions for AIS corrective surgery generally employ more instrumentation as they include longer segments of fixation than anterior fusions, ${ }^{12}$ which probably plays a role in the higher cost of these procedures.

The 2.8-fold increase in the mean hospital charges for AIS surgery is alarming but may be explained by general health care inflation. To examine this possibility, we investigated all patients within the KID, regardless of admission diagnosis. We identified a 1.9-fold increase in hospital charges for all-comers, compared with the 2.8-fold increase for AIS surgery. Furthermore, the increase in charges for patients with AIS appears to be greater than that for patients undergoing other spine procedures. ${ }^{7}$ For example, in a review of patients with C-2 fracture who had undergone surgical procedures, Daniels et al. found that mean charges increased from $\$ 70,781$ in 2000 to $\$ 133,064$ in 2010, a 1.9-fold increase over 11 years. This finding is in contrast to the nearly 3 -fold increase in charges for patients with AIS. These rises in charges may be caused, at least in part, by the increased use of advanced technology such as dense pedicle screw constructs, surgical navigation, and recombinant human bone morphogenetic protein utilization. ${ }^{1,13,16,17,20}$

The trend toward posterior-based surgical techniques may be attributed to a number of different factors, including a perception of fewer complications $\mathrm{s}^{2,5}$ and decreased LOS $^{9}$ associated with segmental posterior instrumentation procedures. Furthermore, ongoing advances in posterior instrumentation technology have increased the ability to correct severe deformity through posterior techniques with 3-column osteotomies such as vertebral column resection. And because posterior surgical approaches for spine deformity surgery have become more popular, future spine surgeons may receive less training in anterior or anteroposterior techniques, which will further propagate this phenomenon.

This study has several potential limitations. The HCUP KID is based on billing data. An examination of curve severity or a detailed analysis of patient complexity was not possible. Care should be taken when comparing the cost and complications of posterior versus anterior surgery, as the posterior fusion group may represent a healthier population with less severe spinal deformity. Additional inherent limitations of the HCUP database include a lack of outpatient data, a probable underestimation of inpatient complications, and a lack of complete granularity regarding the severity of illness and the surgical techniques performed. ${ }^{8,27,34}$ Furthermore, hospital charge data do not equate to hospital cost data; hospital charges have been increasing more rapidly than costs. ${ }^{7}$ Despite these limitations, the data remain important as a basis for further investigation into trends in the surgical treatment of AIS and the rising charges associated with these procedures.

\section{Conclusions}

In summary, over the course of a 15 -year study period, the proportion of posterior fusions performed for AIS increased compared with anterior and anteroposterior procedures. Mean charges for the treatment of AIS increased, with a national bill of more than $\$ 1.1$ billion per year in 2012. The number of comorbid conditions per patient and thus the medical complexity of patients treated for AIS have increased. Further studies are needed to evaluate the implications, both financial and clinical, of the trend toward posterior-only fusions for AIS corrective surgery.

\section{References}

1. Bennett JT, Hoashi JS, Ames RJ, Kimball JS, Pahys JM, Samdani AF: The posterior pedicle screw construct: 5-year results for thoracolumbar and lumbar curves. J Neurosurg Spine 19:658-663, 2013

2. Betz RR, Harms J, Clements DH III, Lenke LG, Lowe TG, Shufflebarger HL, et al: Comparison of anterior and posterior instrumentation for correction of adolescent thoracic idiopathic scoliosis. Spine (Phila Pa 1976) 24:225-239, 1999

3. Brown CA, Lenke LG, Bridwell KH, Geideman WM, Hasan SA, Blanke K: Complications of pediatric thoracolumbar and lumbar pedicle screws. Spine (Phila Pa 1976) 23:1566-1571, 1998

4. Campbell RM Jr, Hell-Vocke AK: Growth of the thoracic spine in congenital scoliosis after expansion thoracoplasty. $\mathbf{J}$ Bone Joint Surg Am 85-A:409-420, 2003

5. Chaloupka R, Repko M, Tichý V, Leznar M, Krbec M: [Comparison of two surgical methods for treatment of idiopathic thoracic scoliosis - anterior versus posterior approaches.] Acta Chir Orthop Traumatol Cech 79:422-428, 2012 (Czech)

6. Cheung JP, Samartzis D, Cheung KM: A novel approach to gradual correction of severe spinal deformity in a pediatric patient using the magnetically-controlled growing rod. Spine J 14:e7-e13, 2014

7. Daniels AH, Arthur M, Esmende SM, Vigneswaran H, Palumbo MA: Incidence and cost of treating axis fractures in the United States from 2000 to 2010. Spine (Phila Pa 1976) 39:1498-1505, 2014

8. Daniels AH, Arthur M, Hart RA: Variability in rates of arthrodesis procedures for patients with cervical spine injuries with and without associated spinal cord injury. J Bone Joint Surg Am 89:317-323, 2007

9. Geck MJ, Rinella A, Hawthorne D, Macagno A, Koester L, Sides B, et al: Comparison of surgical treatment in Lenke 5C adolescent idiopathic scoliosis: anterior dual rod versus posterior pedicle fixation surgery: a comparison of two practices. Spine (Phila Pa 1976) 34:1942-1951, 2009

10. Gitelman Y, Lenke LG, Bridwell KH, Auerbach JD, Sides BA: Pulmonary function in adolescent idiopathic scoliosis relative to the surgical procedure: a 10-year follow-up analysis. Spine (Phila Pa 1976) 36:1665-1672, 2011

11. Hamill CL, Lenke LG, Bridwell KH, Chapman MP, Blanke $\mathrm{K}$, Baldus C: The use of pedicle screw fixation to improve correction in the lumbar spine of patients with idiopathic scoliosis. Is it warranted? Spine (Phila Pa 1976) 21:1241-1249, 1996

12. Helenius I: Anterior surgery for adolescent idiopathic scoliosis. J Child Orthop 7:63-68, 2013

13. Jain A, Kebaish KM, Sponseller PD: Factors associated with use of bone morphogenetic protein during pediatric spinal fusion surgery: an analysis of 4817 patients. J Bone Joint Surg Am 95:1265-1270, 2013

14. Kepler CK, Meredith DS, Green DW, Widmann RF: Long- 
term outcomes after posterior spine fusion for adolescent idiopathic scoliosis. Curr Opin Pediatr 24:68-75, 2012

15. Larson AN, Fletcher ND, Daniel C, Richards BS: Lumbar curve is stable after selective thoracic fusion for adolescent idiopathic scoliosis: a 20-year follow-up. Spine (Phila Pa 1976) 37:833-839, 2012

16. Larson AN, Polly DW Jr, Guidera KJ, Mielke CH, Santos ER, Ledonio CG, et al: The accuracy of navigation and 3D image-guided placement for the placement of pedicle screws in congenital spine deformity. J Pediatr Orthop 32:e23-e29, 2012

17. Lykissas MG, Jain VV, Nathan ST, Pawar V, Eismann EA, Sturm PF, et al: Mid- to long-term outcomes in adolescent idiopathic scoliosis after instrumented posterior spinal fusion: a meta-analysis. Spine (Phila Pa 1976) 38:E113-E119, 2013

18. Martin CT, Pugely AJ, Gao Y, Mendoza-Lattes SA, Ilgenfritz RM, Callaghan JJ, et al: Increasing hospital charges for adolescent idiopathic scoliosis in the United States. Spine (Phila Pa 1976) 39:1676-1682, 2014

19. McMaster MJ, McMaster ME: Prognosis for congenital scoliosis due to a unilateral failure of vertebral segmentation. J Bone Joint Surg Am 95:972-979, 2013

20. Mueller TL, Miller NH, Baulesh DM, Hastings LH, Chang FM, Georgopoulos G, et al: The safety of spinal pedicle screws in children ages 1 to 12. Spine J 13:894-901, 2013

21. Mukaiyama K, Takahashi J, Hirabayashi H, Ogihara N, Kuraishi S, Shimizu M, et al: Factors influencing the residual rib hump after posterior spinal fusion for adolescent idiopathic scoliosis with Lenke 1 and 2 curves. J Orthop Sci 18:687-692, 2013

22. Obid P, Bevot A, Goll A, Leichtle C, Wülker N, Niemeyer T: Quality of life after surgery for neuromuscular scoliosis. Orthop Rev (Pavia) 5:e1, 2013

23. Pehrsson K, Larsson S, Oden A, Nachemson A: Long-term follow-up of patients with untreated scoliosis. A study of mortality, causes of death, and symptoms. Spine (Phila Pa 1976) 17:1091-1096, 1992

24. Powell ET IV, Krengel WF III, King HA, Lagrone MO: Comparison of same-day sequential anterior and posterior spinal fusion with delayed two-stage anterior and posterior spinal fusion. Spine (Phila Pa 1976) 19:1256-1259, 1994

25. Ristolainen L, Kettunen JA, Heliövaara M, Kujala UM, Heinonen A, Schlenzka D: Untreated Scheuermann's disease: a 37-year follow-up study. Eur Spine J 21:819-824, 2012

26. Rushton PR, Grevitt MP: Comparison of untreated adolescent idiopathic scoliosis with normal controls: a review and statistical analysis of the literature. Spine (Phila Pa 1976) 38:778-785, 2013
27. Schneeweiss S, Avorn J: A review of uses of health care utilization databases for epidemiologic research on therapeutics. J Clin Epidemiol 58:323-337, 2005

28. Sudo H, Ito M, Kaneda K, Shono Y, Abumi K: Long-term outcomes of anterior dual-rod instrumentation for thoracolumbar and lumbar curves in adolescent idiopathic scoliosis: a twelve to twenty-three-year follow-up study. J Bone Joint Surg Am 95:e49, 2013

29. Weinstein SL, Dolan LA, Spratt KF, Peterson KK, Spoonamore MJ, Ponseti IV: Health and function of patients with untreated idiopathic scoliosis: a 50-year natural history study. JAMA 289:559-567, 2003

30. Weiss HR, Goodall D: Rate of complications in scoliosis surgery - a systematic review of the Pub Med literature. Scoliosis 3:9, 2008

31. Winter RB: Severe neurofibromatosis kyphoscoliosis, posterior wedge osteotomy, halo-traction, and anterior autograft strut fusion, with 28-year follow-up. Spine (Phila Pa 1976) 36:E1774-E1777, 2011

32. Winter RB, Lonstein JE: Congenital thoracic scoliosis with unilateral unsegmented bar and concave fused ribs: rib osteotomy and posterior fusion at 1 year old, anterior and posterior fusion at 5 years old with a 36-year follow-up. Spine (Phila Pa 1976) 32:E841-E844, 2007

33. Xue X, Shen J, Zhang J, Zhao H, Li S, Wang Y, et al: An analysis of thoracic cage deformities and pulmonary function tests in congenital scoliosis. Eur Spine $\mathbf{J}$ [epub ahead of print], 2014

34. Yoshihara H, Yoneoka D: National trends in spinal fusion for pediatric patients with idiopathic scoliosis: demographics, blood transfusions, and in-hospital outcomes. Spine (Phila Pa 1976) 39:1144-1150, 2014

\section{Author Contributions}

Conception and design: Vigneswaran, Grabel, Eberson, Daniels. Acquisition of data: Vigneswaran. Analysis and interpretation of data: Vigneswaran, Grabel, Daniels. Drafting the article: Vigneswaran, Grabel, Daniels. Critically revising the article: all authors. Reviewed submitted version of manuscript: all authors. Approved the final version of the manuscript on behalf of all authors: Vigneswaran. Statistical analysis: Vigneswaran. Administrative/technical/material support: Daniels. Study supervision: Daniels.

\section{Correspondence}

Hari Vigneswaran, Department of Orthopaedic Surgery, Rhode Island Hospital, 593 Eddy St., Providence, RI 02903. email: hari_vigneswaran@brown.edu. 